\title{
ALUNOS DE SEXTA SÉRIE PRODUZEM UMA REVISTA ${ }^{1}$
}

\section{Nas aulas de Português, alunos aprendem os processos de produção do texto jornalístico para uma revista informativa}

A produção de uma revista foi um projeto realizado no primeiro semestre de sextas séries com as turmas de 1995 e de 1996. Antes de mais nada, esclarecemos que um projeto é uma unidade didática ampla que engloba vários conteúdos conceituais, procedimentais e atitudinais, de acordo com o modelo estabelecido por César Coll e também utilizado por Ana María Kaufman ${ }^{2}$. Deste modo, trabalhamos com conceitos lingüísticos e comunicacionais, além de educacionais que levaram em conta o cidadão que queremos formar. Elegemos trabalhar com a produção de uma revista a partir do momento em que consideramos a língua na sua função referencial e não só emotiva ou poética ${ }^{3}$ (como os professores de Português têm trabalhado desde sempre, ao priorizarem os textos literários). Afinal, uma revista contém textos informativos, como no caso da notícia, da reportagem, da entrevista e da resenha, e também textos poéticos - caso das crônicas $^{4}$. É sobre a realização deste projeto que nos propomos escrever.

\section{POR QUE UMA REVISTA?}

As revistas, nos seus mais variados tipos, constituem um meio de comunicação a cada dia mais consumido. $\mathrm{O}$ mais interessante é que, ao comprarmos revistas sobre esportes, moda, música, política e variedades,

\section{A AUTORA}

Sílvia Ferreira Lima

Professora de Língua Portuguesa de quintas e sextas séries do primeiro grau na rede de escolas particulares, em São Paulo. Professora na Faculdade Anhembi-Morumbi. nem desconfiamos que elas foram criadas também como meio de divulgar obras literárias e propor questões estéticas. Apareceram em grande variedade a partir do século XIX, como veículo de discussão

1. Projeto realizado na Escola da Vila, em São Paulo, nos primeiros semestres de 1995 e de 1996.

2. É interessante consultar a respeito destas classificações textuais: KAUFMAN, Ana Maria, RODRÍGUEZ, María Elena Santillana. La escuela y los textos. Buenos Aires: Santillana, 1993.

3. JAKOBSON, Roman. Lingüística e comunicação. 14.ed. São Paulo: Cultrix, 1991. 162p

4. KAUFMAN, Ana Maria; RODRÍGUEZ, María Elena Santillana. op. cit. 
e apresentação de todos os estilos estéticos que antecederam ao que se convencionou chamar de Modernismo. Inicialmente, esta profusão de formas, cores, imagens e recursos gráficos que caracterizam as revistas atuais não existiam, por isso a linguagem verbal, ou seja, os textos, predominava. Porém, não quaisquer tipos de texto, e sim os ensaios, os poemas e os textos literários em geral, estando mais próximos da função poética do que da função referencial. Trazer para as aulas de Português este meio de comunicação, ou como vamos chamar doravante de portador de texto, passou a ser ainda mais significativo pelas seguintes razões: origem literária, uso comum por diversos tipos de leitor (o que garante o vínculo social), atualidade e suporte de várias linguagens (a escrita, a fotográfica, a diagramação, o desenho, a charge etc.).

\title{
QUE TIPOS DE TEXTO?
}

Nos dois anos de execução do projeto trabalhamos com notícias, reportagens, entrevistas, resenhas e crônicas, além do sumário e do editorial, deixando de fora os quadrinhos, a charge e os textos publicitários.

Selecionamos trabalhar com notícias, pois estas contêm a mesma estrutura da narrativa ficcional: onde, quando, quem e como - lugar, tempo, personagens e enredo. A diferença entre estes tipos de texto é que o primeiro se detém aos fatos enquanto o segundo, à linguagem. Além disso, a notícia é efêmera e no caso de uma revista ela será apenas parte da reportagem (que é um texto mais longo, podendo ter matrizes narrativa, descritiva e dissertativa, além de uma junção destas).

\section{Sexo na adolescência \\ e doenças sexualmente transmissíveis}

\author{
Thaís, Thereza, Joana, \\ Eduardo, Renato e Maurício
}

A puberdade é o fenômeno que marca a passagem da vida infantil para a fase adulta. Nos homens a puberdade acontece dos 13 aos 17 anos e nas mulheres dos 11 aos 17 anos. Nessa fase podem aparecer muitas desconfianças, pois começam a acontecer grandes modificações, como: crescem pelos no púbis, começam a aparecer os seios (nas meninas) e barba (nos meninos) e a grande inimiga de todo o adolescente "a espinha"; elas ocorrem quando as glândulas sebáceas são invadidas por um tipo de organismo e assim inflamam. Para evitá-las é necessário deixar o corpo bem limpo, lavar o rosto várias vezes ao dia e, principalmente, não espremê-las. Quando as meninas entram na puberdade pode ocorrer o fato de um seio crescer mais que o outro, causando um pouco de vergonha.

Os alunos da sexta série B. Thais Morena Tardone, Thereza Oliveira Farkas, Joana Paulino, Eduardo O. Fernandes, Renato Noffs Gilio e Maurício Sodré Ribeiro, fazem, para a revista Tudo, a reportagem Sexo na adolescência e doenças sexualmente transmissíveis. 
É também a oportunidade para se trabalhar a ordem direta das frases - sujeito, predicado e complementos - além de toda a sintaxe do período simples, sem contar os aspectos de edição tais como: composição de título, subtítulo, antetítulo, olho, legendas, fotos e outras ilustrações.

Com esses tipos de texto focalizamos as funções da linguagem e os níveis de linguagem. $\mathrm{O}$ mesmo exercício pode ser feito com a produção de entrevistas. Elas tanto podem fazer parte das reportagens como virem na forma de pingue-pongue como uma seção específica dentro da revista (é o que observamos nas Páginas Amarelas da revista Veja, ou da seção Entrevista de Comunicação \& Educação, por exemplo), sem contar a presença de elementos da oralidade e da escrita no mesmo tipo de texto.

Sào Paulo, 20 de Maio de 1996

$$
\text { ENTREVISTA. EDITH DERDYK }
$$

EDITH DERDYK CONQUISTOU O MUNDO DAS ARTES PLÁSTICAS

Ela representou o Brasil num importante evento de Copenhagen, e conta um pouco de sua carreira para nós.

Edith Derdyk wem se preocupando cam o desenho de maneira profunda e abrangen. te, tanto como artista, criadora de uma expressâo pessoal, ou como intelectual estudando os elementos formadores da linguagem nas artes plásticas....

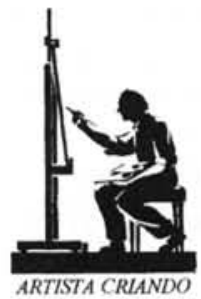

Foi assim que Fábio Magalhâes retratod a fantástica arte desta artista, mas ele esqueceu de falar das belas formas por ela conquistadas, da magia dos tracos por ela desenvolvidos e das lindas cores por ela harmónicamente encaixadas na obra.

Tambeim nî̃o foram ditas as várias exposiçôes realizadas sendo 6 individuais e II coletivas: dos 4 prémios consecutivos conquistados e de sua principal conquista, ser essa fabulosa pessoa que ela é.

Ao voltar de Copenhagen, pela sua participaça de um importante evento cultural, cla nos deu a honra de entrevistá-la.

Carlos Fiduardo Baldo Carlomagno
Gabriela Nagata Castelo

Laura Gianersella Galwão Patricta Camargo Magalhates

Rafael Terro Junqueira

Vila- Com que tipo de material você trabalha?

Derdyk- Ultimamente tenho trabalhado com plástico, linha de costura e papel Japonês.

Vila- Onde surgiu a idéia de usar esses materiais? De onde vocè se inspira para fazer os seus trabalhos?

Derdyk- Tenho desenvolvido um trabalho que utiliza a costura para a construção de objetos e esculturas. Daí a necessidade de utilizar materiais maleáveis e flexíveis, que possam ser costurados como o plástico e o papel Japonès que é bem leve, fino $\mathrm{c}$ transparente. Estes objetos c esculturas, muitas vezes lembram elementos orgânicos como casulos, pedras, ninhos e conchas. É interessante utilizar materiais industriais como o plástico que lembra a natureza.

Vila- Como vocé se sente representando o Brasil num evento cultural em Copenhagen? Vocé jả esperava esse reconhecimento de sua arte?

Derdyk- É muito importante quando o seu trabalho artistico ganha uma dimensâo cultural, ou seja,

Edith Derdyk, artista plástica, é entrevistada pelos alunos da sexta série A: Gabriela Nagata Castelo, Laura Gianessella Galvão, Patrícia Camargo Magalhães e Rafael Terra Junqueira, repórteres da revista IstoFoi. 
Já a produção de resenhas faz parte de um trabalho de leitura de vários títulos opcionais, em média um por mês. Os alunos escolhem um livro, lêem e produzem uma observação crítica e uma recomendação, mais ou menos no estilo das resenhas de livros, peças teatrais e shows.

Quanto às crônicas, por serem textos oriundos de um gênero híbrido, mistura de literatura e notícia, dada sua condição de narrativa de acontecimentos diários, podem subsidiar o estudo das figuras de linguagem: metáfora, metonímia e ironia.

O editorial - texto predominantemente argumentativo (dissertação), cuja função é a de comentar a revista, pode incluir a descrição do seu processo, a história daquele número (narração) ou propor discussão e emitir opiniões relacionadas com as matérias daquela edição - foi feito no final, quando os alunos já haviam produzido todo o conjunto: matérias e ilustrações. Os alunos escolheram escrever editoriais nos quais prevaleceram a descrição e a narração do processo de produção da revista em relação à emissão de opinião sobre os fatos tratados no corpo da publicação.

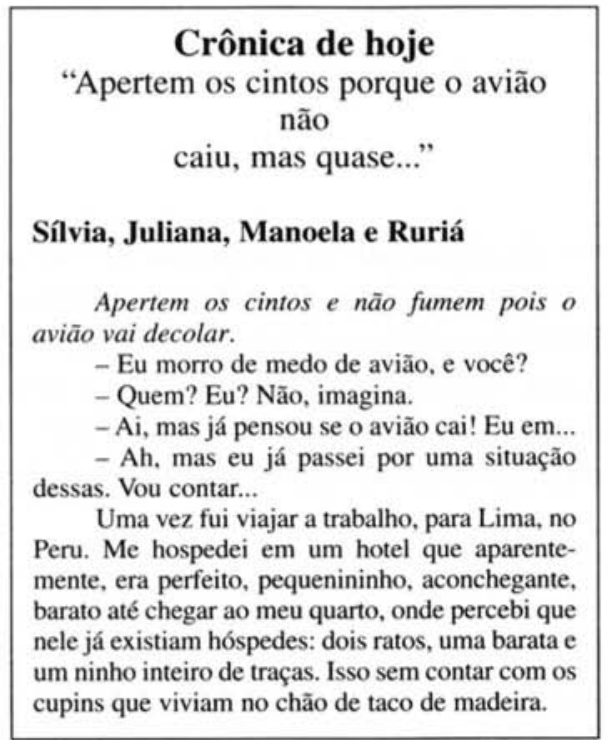

Os alunos da sexta série B, Sílvia Santa Cruz Brein, Juliana Cossignani, Manoela Salém Miklos e Ruriá Gama Azzi, prodıziram, para a revista Tudo, a Crônica de Hoje.

\section{CONTEÚDOS TRABALHADOS}

Neste projeto, trabalhamos com os conteúdos lingüísticos: sintaxe de períodos simples, por exemplo, principalmente nas notícias; discurso direto e indireto, que aparecem nas entrevistas e nas citações de algumas personagens envolvidas ou entrevistados; pontuação adequada: ponto, vírgula, ponto e vírgula, exclamação, interrogação e aspas; elementos de teoria literária: personagens, tempo, lugar, enredo (ação e clímax) e narrador; figuras de linguagem, funções da linguagem e níveis de linguagem; elementos de teoria da comunicação, como a clássica pirâmide invertida da informação. 
Essa é a pirâmide que aparece, por exemplo, nos textos de jornais e de revistas, pois a informação se processa com muita rapidez e é importante prender a atenção do leitor. Por isso os dados principais do fato, que respondem às perguntas o quê, quem, onde, quando e por quê aparecem no primeiro parágrafo, enquanto o como vai se apresentando ao longo dos textos.

Para finalizar a revista, os alunos também tomam conhecimento do processo de edição: título, subtítulo, intertítulo, olho, nome da revista e das seções no alto da página, além de se colocarem, na prática, com a responsabilidade de fazer a seleção de qual informação, entre as várias produzidas por eles, é mais relevante para a publicação.

A proposta é garantir que os alunos sejam autores conscientes de que o perfil do leitor, a quem se dirigem, define o tipo de texto que deverá ser produzido, de modo a garantir uma comunicação efetiva e de maior vínculo social.

\section{AS ETAPAS}

A exploração e o conhecimento do processo de produção de uma revista é o primeiro passo para que se possa planejar o trabalho que os alunos farão no decorrer do projeto. A discussão sobre os tipos de texto encontrados neste portador é a próxima etapa. A seguir se define o leitor a que se dirigirá, bem como o nome da revista, os tipos de texto e assuntos abordados, além do número de páginas da publicação e o número de páginas de cada matéria.

A partir daí, os alunos tomam contato com vários tipos de notícias, reportagens, entrevistas, crônicas e resenhas, estudando sua macro e microestrutura, para produzi-los posteriormente. Depois da redação das matérias, seguem-se as etapas de revisão: individual, em grupo, feita pelo aluno, feita pelo professor. Leva-se em conta, neste processo, a pertinência e adequação de cada uma das matérias com relação aos conteúdos estudados e discutidos, enfocados a cada leitura. Depois de revisadas, corrigidas, ilustradas e diagramadas, alguns grupos de alunos são escolhidos para selecionar matérias, tendo em mente o perfil editoral já discutido, além do número de páginas pré-estabelecidas para cada texto e cada seção. Selecionados os textos de modo a se garantir que haja pelo menos uma contribuição de cada um dos alunos, dá-se início à numeração das páginas, à confecção da capa e contracapa bem como à produção do índice. Tudo preparado, o próximo passo é montar as páginas e a revista estará pronta para ser copiada (xerox) e disribuída. 

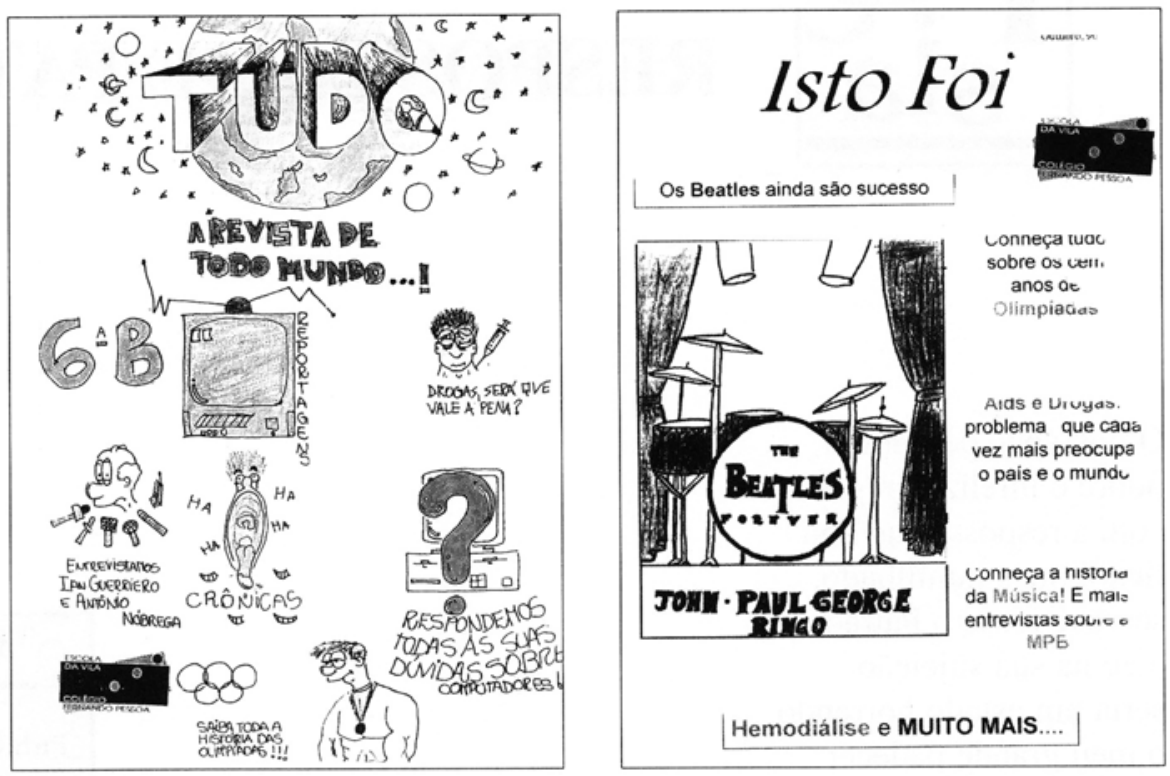

As revistas Tudo, da sexta série B, e IstoFoi, da sexta série A são produtos de um conjunto de aprendizados que não se limitam ao Português.

É importante que os alunos participem parte de todas as etapas do processo de elaboração, inclusive da montagem final da revista, pois eles passam a conhecer toda a

Resumo: Professora de Português relata experiência pedagógica desenvolvida com alunos de sexta série do primeiro grau, na qual discute, analisa e elabora, junto com os alunos, todo o processo de produção dos diferentes textos jornalísticos, resultando na produção de uma revista.

Palavras-chave: Ensino de Português, revista, produção de texto, jornalismo dinâmica e se sentem donos do processo de aprendizagem, incorporando os conteúdos que se quis passar de forma mais autônoma, significativa e duradoura.

Abstract: Professor of Portuguese reports on a pedagogical experience carried out among sixth grade students in which the entire process of producing the different journalistic texts, resulting in the production of a magazine, is discussed, analyze and elaborated alongside the students.

Keywords: Portuguese teaching, magazine, text production, journalism 